\title{
Audition-Independent Vocal Crystallization Associated with Intrinsic Developmental Gene Expression Dynamics
}

\author{
Chihiro Mori ${ }^{1}$ and ${ }^{\oplus}$ Kazuhiro Wada ${ }^{1,2,3}$ \\ ${ }^{1}$ Graduate School of Life Science, ${ }^{2}$ Department of Biological Sciences, and ${ }^{3}$ Faculty of Science, Hokkaido University, Sapporo, Hokkaido, 060-0810, Japan
}

\begin{abstract}
Complex learned behavior is influenced throughout development by both genetic and environmental factors. Birdsong, like human speech, is a complex vocal behavior acquired through sensorimotor learning and is based on coordinated auditory input and vocal output to mimic tutor song. Song is primarily learned during a specific developmental stage called the critical period. Although auditory input is crucial for acquiring complex vocal patterns, its exact role in neural circuit maturation for vocal learning and production is not well understood. Using audition-deprived songbirds, we examined whether auditory experience affects developmental gene expression in the major elements of neural circuits that mediate vocal learning and production. Compared with intact zebra finches, early-deafened zebra finches showed excessively delayed vocal development, but their songs eventually crystallized. In contrast to the different rates of song development between the intact and deafened birds, developmental gene expression in the motor circuit is conserved in an agedependent manner from the juvenile stage until the older adult stage, even in the deafened birds, which indicates the auditionindependent robustness of gene expression dynamics during development. Furthermore, even after adult deafening, which degrades crystallized song, the deteriorated songs ultimately restabilized at the same point when the early-deafened birds stabilized their songs. These results indicate a genetic program-associated inevitable termination of vocal plasticity that results in audition-independent vocal crystallization.
\end{abstract}

Key words: critical period; deaf; motor pattern generation; sensorimotor learning; songbird; species specificity

\section{Introduction}

Songbirds and humans learn vocalization to communicate through sounds by tutor mimicry and sensory feedback. The learning of birdsong, a complex sequenced motor pattern, occurs within a defined critical period during which juvenile songbirds listen, memorize, and gradually match their own developing vocalizations to the song of an adult tutor. The brain areas associated with song learning and production, the song nuclei, are organized into two major circuits: (1) the posterior vocal motor circuit and (2) the anterior basal ganglia-forebrain circuit. The vocal motor circuit receives direct projections from auditory areas (Bauer et al., 2008) and participates in song pattern generation in a hierarchical manner by regulating syllable sequences and acoustic features ( $\mathrm{Yu}$ and Margoliash, 1996; Hahnloser et al., 2002). In contrast, the basal ganglia-forebrain circuit, also called the anterior forebrain pathway (AFP), plays a critical role in song

\footnotetext{
Received May 3, 2014; revised Nov. 12, 2014; accepted Nov. 15, 2014

Author contributions: C.M. and K.W. designed research; C.M. performed research; C.M. and K.W. analyzed data; C.M. and K.W. wrote the paper.

This work was supported by Grant-in-Aid for Japan Society for the Promotion of Science Fellows 11J07071 (C.M.) and the Uehara Memorial Foundation, the Asahi Glass Foundation, Grant for Basic Science Research Project from the Sumitomo Foundation, and Grants-in-Aid for Scientific Research 21681024, 21115501, and 25290063 (K.W.). We thank Dr. A. Watanabe for advice on the deafening operation; Drs. H. Horita, W.-C. Liu, S. Yanagihara, and S. Kojima for providing critical comments; Dr. M. Soma for statistical advice; Dr. K. Suzuki for advice on analysis using K-L distance; and A. Kamimura for advice on DNA microarray experiments.

Correspondence should be addressed to Kazuhiro Wada, Faculty of Science, Department of Biological Sciences, Hokkaido University, Room 910, Building 5, North 10, West 8, Kita-ku, Sapporo, Hokkaido 060-0810, Japan. E-mail: wada@sci.hokudai.ac.jp.

DOI:10.1523/JNEUROSCI.1804-14.2015

Copyright $\odot 2015$ the authors $\quad 0270-6474 / 15 / 350878-12 \$ 15.00 / 0$
}

learning by producing the vocal exploration necessary for audition-dependent vocal plasticity (Bottjer et al., 1984; Scharff and Nottebohm, 1991; Brainard and Doupe, 2000; Andalman and Fee, 2009).

Developmental epigenetic factors, such as social interaction (Kroodsma and Pickert, 1984) and nutrition (Nowicki et al., 2002), influence vocal learning. In addition, an auditory input is crucial for the acquisition of birdsong and human speech as an epigenetic factor for sensorimotor learning (Konishi, 1965; Ruben, 1997). Audition provides important information for vocal learning, both for hearing model songs and precise evaluation of own vocal output. However, audition-deprived songbirds can still develop a certain degree of species-specific song, albeit noisy and amorphous (Price, 1979; Marler and Sherman, 1983). This suggests that inherited genetic predisposition also contributes to song development and the generation of song patterns, but the mechanism by which auditory input regulates the genetic programs in neural substrates mediating development and stabilization of complex vocal patterns remains unclear.

Here we investigate the neural molecular mechanisms contributing to song development by comparing song output and intrinsic gene expression profiles within song nuclei between the intact and audition-deprived zebra finches. The zebra finch is known as a closed-ended learner of complex vocal patterns given that, once a stable song pattern "motif" is developed, the song structure remains unchanged throughout life (Immelmann, 1969; Eales, 1985; Zann, 1996). This stereotypy of crystallized song enables precise quantification of the similarities and differ- 
ences in vocal development and song patterns between the intact and deafened birds, thus allowing examination of how genetic and epigenetic factors contribute to acquisition and maintenance of complex vocal patterns. We showed that early-deafened zebra finches can still develop crystallized songs but do so more slowly than the intact birds. Eventual development of crystallized songs in the deafened birds is correlated with audition-independent changes in gene expression that continue to emerge well beyond sexual maturity. These results provide evidence for audition-independent regulation of vocal development and crystallization associated with intrinsic developmental gene expression dynamics.

\section{Materials and Methods}

Animals. We used male zebra finches from our breeding colony ranging from 47 to $1780 \mathrm{~d}$ post-hatching (dph). The photoperiod was constantly maintained at a 14/10 h light/dark cycle with food and water provided ad libitum. The sex of birds was checked by PCR as reported previously (Wada et al., 2006) within $3 \mathrm{~d}$ after hatching. The birds were raised in individual breeding cages with their parents and siblings until at least dph 30 and were then housed in single-sex groups (6-10 birds per cage) with visual and auditory access to both the male and female birds. We divided the animals into the following developmental stages to examine ageassociated changes: (1) dph 47-65, juvenile; (2) dph 100-187, young adult; and (3) $>$ dph 300, older adult. For social isolation, the juveniles were separated from their fathers by dph 5 and raised by their mothers with their siblings in a sound-attenuation box until they could feed themselves (dph 35). No song tutor was provided, and they could not see the other zebra finches or hear other songs after dph 35. All animal experiments were performed according to the guidelines of the Committee on Animal Experiments of Hokkaido University from whom permission for this study was obtained. The guidelines are based on national regulations for animal welfare in Japan (Law for the Humane Treatment and Management of Animals; after partial amendment number 68, 2005).

Song recording and analysis. The birds were individually housed in sound-attenuation boxes (box size, $65 \times 27 \times 30 \mathrm{~cm}$; cage size, $54 \times$ $22 \times 23 \mathrm{~cm}$ ). Songs were automatically saved $24 \mathrm{~h} / \mathrm{d}$ using the Sound Analysis Pro program (version 1.04) (Tchernichovski et al., 2000) at 16 bits and a $44 \mathrm{kHz}$ sampling rate. Analysis of syllable acoustic structure was performed using Sound Analysis Pro and Avisoft Saslab (Avisoft Bioacoustics). Low- and high-frequency noises $(<0.5$ and $>1.9 \mathrm{kHz})$ were filtered from the recordings using Avisoft Saslab, and the lowfrequency noises $(<1.5 \mathrm{kHz})$ were further filtered using Sound Analysis Pro. For all analyses, we randomly selected songs per time point and manually eliminated calls and cage noise from the dataset. The entropy and amplitude parameters of syllables were set manually, and the syllables were segmented using Sound Analysis Pro. A song bout was defined as the continuous production of syllables, followed by at least $400 \mathrm{~ms}$ of silence. Typical song bouts in adult zebra finches start with introductory notes, followed by one or more motifs that consist of the same stereotyped sequence of syllables.

To measure the degree of song stabilization, we calculated song similarity by the Kullback-Leibler (K-L) distance analysis (Wu et al., 2008) between song at each developmental stage and at $>1$ year of age. The $\mathrm{K}-\mathrm{L}$ distance analysis compares the probability density function from two large sets of syllables and quantifies the difference. Syllable density scatter plots were treated as random samples from a two-dimensional probability distribution. For construction of two-dimensional scatter plots with syllable duration and mean frequency modulation, we used 600-1000 syllables (mean \pm SD, $982 \pm 68$ ) at each developmental stage for each bird. The two-dimensional scatter plot was partitioned into an $M \times N$ array of bins. To obtain an accurate and consistent estimation of the distribution, $M$ and $N$ were kept constant throughout all days of singing. The number of data points in each bin was counted and divided by the total number of points in the plot. We represented the two-dimensional scatter plot generated at $>1$ year of age by $P_{s}$ and the scatter plot at each developmental stage as $P_{k}$. The difference between $P_{s}$ and $P_{k}$ was calculated to obtain the estimate probability density functions (denoted $Q_{s}$ and $Q_{k}$ ) for the two scatter plots. The $\mathrm{K}-\mathrm{L}$ distance is represented by the following equation:

$$
D_{\mathrm{KL}}\left(Q_{s} \| Q_{k}\right)=\sum_{m=s}^{M} \sum_{n=s}^{N} q_{s}(m, n) \log _{2} \frac{q_{s}(m, n)}{q_{k}(m, n)},
$$

where $q_{s}(m, n)$ and $q_{k}(m, n)$ denote the estimated probabilities for bin $(m, n)$. Large values of the $\mathrm{K}-\mathrm{L}$ distance indicate that the two patterns are more dissimilar, whereas a $\mathrm{K}-\mathrm{L}$ distance of 0 indicates a perfect match. We normalized the $\mathrm{K}-\mathrm{L}$ distance value to the average $\mathrm{K}-\mathrm{L}$ distance at the first stage of development (dph 49-59) for each experimental group. We used 15 male birds (intact, $n=4$; early-deafened, $n=6$; socially isolated, $n=5$ ) for the $\mathrm{K}-\mathrm{L}$ distance analysis.

To examine the correlation between amount of singing and expression level of immediate early genes as neural activity-dependent gene markers, we measured total singing duration (time spent producing songs) before brain sampling. We counted the number of bouts of singing within a day at least $1 \mathrm{~d}$ after the bird (either intact or deafened) was put into a sound-attenuated box ( 20 juveniles, $n=10$ per group; 19 young adults, $n=9-10$ per group; 21 older adults, $n=$ 10-11 per group).

To compute correlations between song traits and DNA microarray expression data, we calculated mean values and coefficients of variation (CVs) of nine song parameters for each bird from 100 syllables recorded within 1 week before brain sampling: (1) syllable duration; (2) amplitude; (3) pitch; (4) frequency modulation (FM); (5) Wiener entropy; (6) goodness of pitch; (7) intersyllable duration; (8) syllable number in a motif; and (9) motif consistency. Motif consistency was measured as motif similarity score within $1 \mathrm{~d}$ and was calculated by the default setting in the Sound Analysis Pro software using the "time course" and "symmetric" comparison modes. This procedure can calculate the similarity score between two motifs on the basis of comparison of syllable acoustic features (e.g., pitch, FM, amplitude modulation, Wiener entropy, and goodness of pitch) within sliding $9 \mathrm{~ms}$ time windows and represents a global measure of percent similarity. For motif consistency analysis, song motifs were extracted from sequences of three to five syllables at the beginning of the bout but excluding introductory notes. We compared 20 randomly selected motifs in each bird.

Measurement of testosterone levels. We measured the serum concentration of circulating testosterone in the male juveniles $(n=16,8$ per group), young adults ( $n=20,10$ per group), and older adults ( $n=20,10$ per group) to examine whether early-stage deafening affects the rate of maturation. Blood was sampled before lights on (morning) under silent conditions. Blood serum was isolated by centrifuging whole blood for 15 min at room temperature and was stored at $-30^{\circ} \mathrm{C}$ until testosterone analyses. The blood serum samples were diluted by ARCHITECT Testosterone Manual Diluent (Abbott Laboratories), and testosterone levels were measured by BML.

Deafening. The birds were deafened by cochlear extirpation at dph 17-23 (before fledging) to establish the early-deafened group or at dph 92-157 (after song crystallization) to establish the adult deafened group. The birds were anesthetized with pentobarbital $(6.48 \mathrm{mg} / \mathrm{ml} ; 60 \mu \mathrm{l} / 10 \mathrm{~g}$ body weight) by intraperitoneal injection. After fixing the head in a custom-made stereotaxic apparatus with ear bars, a small window was made through the neck muscle and the skull near the end of the elastic extension of the hyoid bone. A small hole was then made in the cochlear dome. The cochlea was pulled out with a fine hooked wire. The removed cochleae were confirmed by visual inspection under a dissecting microscope. After bilateral cochlear removal, the birds were put back in their nest and kept with their parents and siblings until dph 32-41.

Brain lesion and its evaluation. We used 16 adult male birds for lesion experiments (intact, $n=8$; early-deafened, $n=8$ ). Songs recorded at least $2 \mathrm{~d}$ before surgery are referred to as $\mathrm{HVC}$ (used as a proper name; the motor circuit)-intact songs. The bilateral HVC was lesioned by local injection of $0.44 \mu \mathrm{l}$ of $1 \%$ ibotenic acid dissolved in $1 \mathrm{M} \mathrm{NaCl}$ using a Nanoject 2 injector (Drummond Scientific). Songs were then rerecorded multiple times starting after 1 week of surgery. To examine the effect of lesions on singing, syllable duration distributions were calculated using 700 syllables. 
To confirm lesioned areas, the anesthetized birds were perfused with $1 \times$ PBS and then $4 \%$ paraformaldehyde/1× PBS. Sagittal sections, 30 $\mu \mathrm{m}$ thick, were cut on a freezing microtome and were free-floated in $1 \times$ PBS. The brain sections were then transferred to $0.3 \% \mathrm{H}_{2} \mathrm{O}_{2} / 1 \times$ PBS for peroxidase inactivation, washed three times with $1 \times \mathrm{PBS}$, and reacted overnight at $4^{\circ} \mathrm{C}$ in blocking solution containing mouse anti-NeuN monoclonal antibody (1:2000; Millipore). After three washes with $1 \times$ PBS, the sections were incubated in biotinylated goat anti-mouse IgG serum (1:400; Vector Laboratories), washed three times with $1 \times$ PBS, and then submerged in avidin-biotin-peroxidase complex solution (PK-6101; Vector Laboratories). Antibody labeling was visualized with DAB solution (SK4100; Vector Laboratories). We stained one of every four sections to estimate lesion size and location.

Brain tissue collection. We collected brain samples from the intact and early-deafened zebra finches under the following two conditions: (1) silence and darkness with no singing and just before switching the light on (intact, $n=20$; early-deafened, $n=19$ ); and (2) with singing for $30-60 \mathrm{~min}$ after switching the light on (intact, $n=19$; early-deafened, $n=18$ ). To ensure similar circadian rhythms between the silent and singing conditions, sample collection was performed in the morning. To collect brain samples after singing, all the animals were individually placed in a sound-attenuated box at least $2 \mathrm{~d}$ before singing, and they were subsequently killed by decapitation. In both groups, the brains were rapidly removed, frozen in a plastic mold with Tissue-Tek OCT compound (Sakura Fine Technical), placed on dry ice, and stored at $-80^{\circ} \mathrm{C}$ until use for in situ hybridization or for laser capture microdissection (LCM)

Radioisotopic in situ hybridization and quantification. Serial sagittal sections, $12 \mu \mathrm{m}$ thick, were cut throughout the brain, and ${ }^{35}$ S-labeled riboprobe in situ hybridization was performed as described previously (Wada et al., 2004). We first amplified cDNA fragments [dual-specific phosphatase 1 (Dusp1), Early growth response 1 (Egr1), hairy/enhancerof-split related with YRPW motif protein 1 (Hey1), MAX-interacting protein 1 (Mxi1), neuronal differentiation 6 (Neurod6), sex determining region Y-box 4 (Sox4), and zinc finger protein 238 (Znf238)] by PCR from the zebra finch whole-brain first-strand cDNA and cloned them into pGEMT-easy vectors. PCR was performed to amplify the plasmid region that included the cloned cDNA between T7 and SP6 RNA polymerase binding regions. The resulting PCR fragment was used as the DNA template for T7 or SP6-primed in vitro transcription to synthesize ${ }^{35} \mathrm{~S}$-labeled riboprobes for in situ hybridization. Frozen sections were fixed in $3 \%$ paraformaldehyde/ $1 \times$ PBS, acetylated, dehydrated in an ascending ethanol series, and then hybridized with ${ }^{35} \mathrm{~S}$-labeled riboprobe $\left(1 \times 10^{6} \mathrm{cpm} / \mathrm{slide}\right)$ in hybridization solution $(50 \%$ formamide, $10 \%$ dextran, $1 \times$ Denhardt's solution, 12 mm EDTA, 10 mm Tris HCl, pH 8.0, $30 \mathrm{~mm} \mathrm{NaCl}, 0.5 \mu \mathrm{g} / \mu \mathrm{l}$ yeast tRNA, and $10 \mathrm{~mm}$ DTT) at $65^{\circ} \mathrm{C}$ for $14 \mathrm{~h}$. The slides were then washed and exposed to $\beta$-Max Hyperfilm (Kodak) before being immersed in NTB-2 emulsion (Kodak) for $2-5$ weeks. The slides were then developed and stained with cresyl violet. The signal intensity of mRNAs in song nuclei and other brain regions was calculated by a previously described procedure (Wada et al., 2006). The exposed $\mathrm{x}$-ray films of brain images were digitally scanned under a dissecting microscope (Z16 APO; Leica) connected to a CCD camera (DFC490; Leica) using Application Suite V3 imaging software (Leica). The same light and camera settings were used for all images to facilitate comparison. We used Photoshop (Adobe Systems) to measure the mean pixel intensities in the brain areas of interest from two or more adjacent sections after conversion to a 256 grayscale.

We performed regression analysis using the statistical software $\mathrm{R}$ (http://www.r-project.org/; R Core Team, 2013; R Foundation for Statistical Computing) to compare Dusp1 and Egrl expression levels induced by singing in the AFP between the four experimental groups. To compare expression levels of Hey1, Mxil, Neurod6, Sox4, and Znf238, F tests were first performed to confirm the homoscedasticity of the expression ratio between song nuclei, followed by Student's $t$ tests or Welch's $t$ tests. For all tests, statistical significance was considered at $p<0.05$ after Bonferroni's correction.

$L C M$. The brains were serially cryosectioned at $14 \mu \mathrm{m}$ thick onto handmade membrane slides for LCM. The tissue sections were stained for Nissl bodies to histologically confirm the presence and boundaries of each nucleus and were then dehydrated before LCM. Briefly, frozen sections were sequentially exposed to $75 \% \mathrm{EtOH}$ for 30 s, $50 \% \mathrm{EtOH}$ for $30 \mathrm{~s}$, cresyl violet for $15 \mathrm{~s}, 50 \% \mathrm{EtOH}$ for $30 \mathrm{~s}$, $75 \% \mathrm{EtOH}$ for $30 \mathrm{~s}, 95 \%$ EtOH for 30 s, 100\% EtOH for 30 s, 100\% EtOH for 1 min, 100\% EtOH for $3 \mathrm{~min}, 2 \times 2 \mathrm{~min} x y l e n e$, and finally air dried for $5 \mathrm{~min}$ (LCM Staining kit; Ambion). HVC and the robust nucleus of the arcopallium (RA) tissues were microdissected using a laser capture microscope (ArcturusXT; Arcturus Bioscience). The laser parameters for LCM were as follows: spot diameter, $100 \mu \mathrm{m}$; laser power, $80 \mathrm{~mW}$; and laser duration, $80 \mathrm{~ms}$. The microdissected tissue was directly collected into RLT Buffer from the RNeasy Micro kit (Qiagen) supplemented with $\beta$-mercaptoethanol. The samples were vortexed, centrifuged, and stored at $-80^{\circ} \mathrm{C}$ until RNA purification.

RNA purification, amplification, and confirmation of the linearity of amplification. We isolated and amplified RNA according to the procedures of the Agilent Gene Expression FFPE Workflow (http://www. chem. agilent.com/Library/applications/5990-3917en_hi.pdf). RNA was column purified (RNeasy Micro kit; Qiagen) and treated with DNase on the column to remove genomic DNA. To quantify RNA quality, RNA integrity number (RIN) and concentration were measured by a Bioanalyzer 2100 (Agilent Technologies). Because of the limited yield of extracted RNA, we randomly selected four RNA samples to examine RIN and RNA concentration (RIN, 5.9-7.1; RNA concentration, 1.69-2.35 ng/ $\mu \mathrm{l})$. Purified RNA was amplified using the TransPlex Whole Transcriptome Amplification kit (WTA2 kit; Sigma-Aldrich) according to the instructions of the manufacturer. The amplified cDNA was purified by removal of residual primers and nucleotides using the QIAquick PCR purification kit (Qiagen). Quality and yield of the amplified cDNA were measured by a NanoDrop ND-8000 (Thermo Fisher Scientific) and by electrophoresis. A $1.7 \mu \mathrm{g}$ sample of total amplified cDNA was converted into Cy3-labeled cDNA using the Genomic DNA ULS labeling kit (Agilent Technologies) following the Agilent Gene Expression FFPE Workflow. Labeled cDNAs from each sample were hybridized to a DNA microarray.

DNA microarrays. Agilent zebra finch $4 \times 44 \mathrm{k}$ oligoarrays (AMADID number 021323 ) containing 44,969 cDNA 60-mer probes (including 11,549 genes as gene-symbol identified genes) were designed at the Jarvis Laboratory of Duke University on the basis of sequence information of cDNA libraries from Duke University, Michigan State University, Rockefeller University, and the Keck Center of the University of Illinois (Wada et al., 2006; Li et al., 2007; Replogle et al., 2008). HVC and RA tissue samples (each $n=3$ at juvenile, young, and old stages) were laser microdissected from the intact and early-deafened birds (for both the intact and early-deafened birds at juvenile, young, and old stages: $n=4,5$, and 3 birds, respectively). Because of experimental difficulty at the RNA amplification step, some birds were used for only HVC or RA (thus, the number of sample birds at some stages exceeded three). Single-channel hybridizations were conducted for each sample that was hybridized to a single array. Because four arrays were printed separately on a slide, we hybridized four samples matched for the age and brain region as a single batch to minimize possible interslide bias or batch effects. After hybridization, the arrays were washed and scanned, and the data were extracted from the scanned images (G2505B; Agilent Technologies) using Feature Extraction version 9.1 (Agilent Technologies). The DNA microarray data reported in this study were deposited in the Gene Expression Omnibus database (accession number GSE56075).

DNA microarray statistical analysis. All subsequent preprocessing and analyses were performed using Microsoft Excel and the statistical software R. Probe refers to a single probe on the array. For the majority of gene-symbol identified genes, multiple probes were present on the array. HVC and RA samples were separated, and the two datasets were preprocessed separately as follows. First, control probes were removed, and probes with raw fluorescence values $>3$ SDs from the mean of all samples for that probe were removed. To reduce noise, probes with raw fluorescence values $<50$ in $>80 \%$ of samples in each nuclei were removed. A total of 41,525 probes for 11,391 gene-symbol identified genes in HVC and 41,340 probes for 11,374 gene-symbol identified genes in RA fit these 


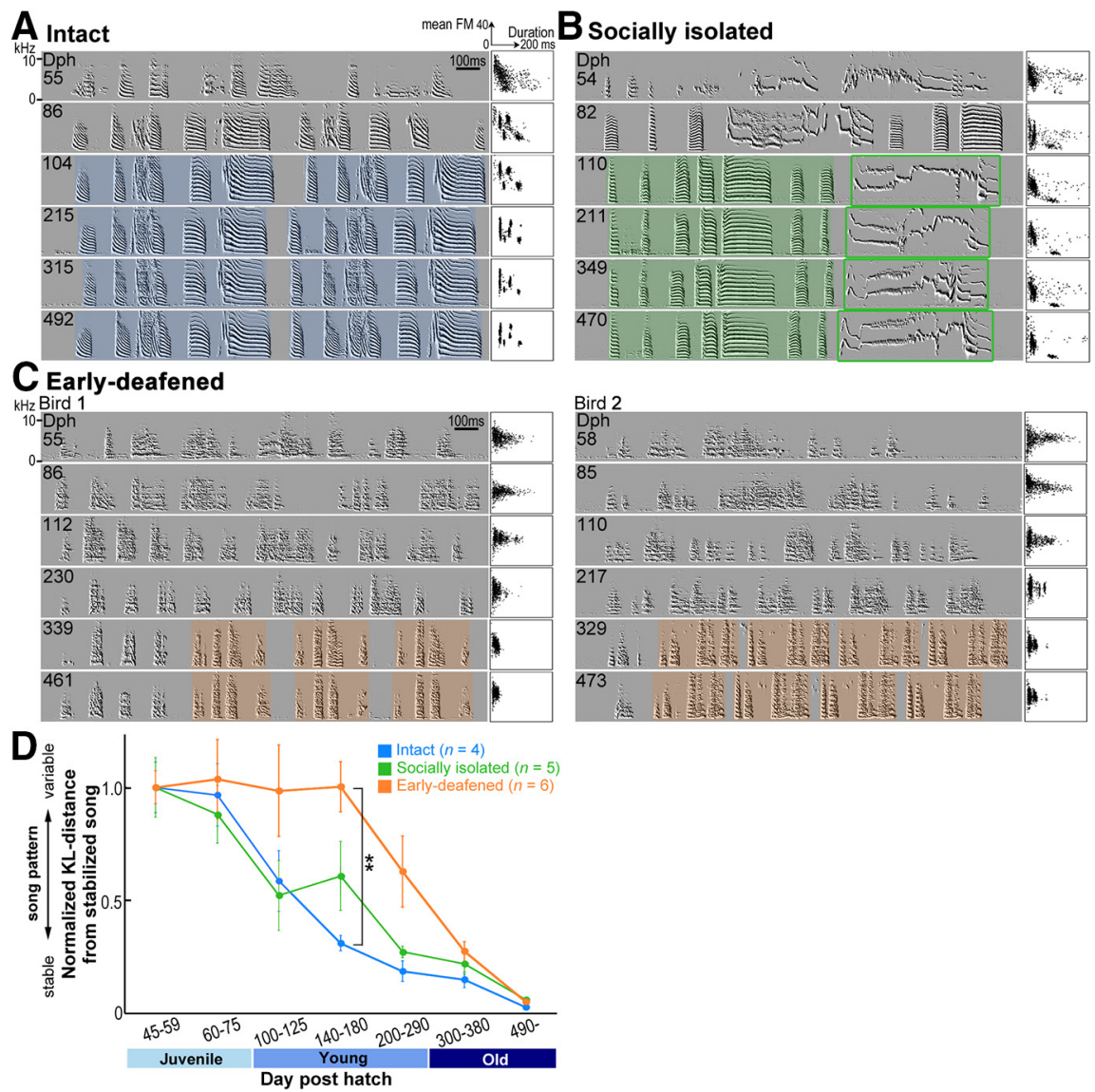

Figure 1. Comparison of song development and stabilization in intact, socially isolated, and early-deafened zebra finches. $\boldsymbol{A}, \boldsymbol{B}$, Examples of song development and syllable scatter plots (duration vs mean FM) in an intact ( $\boldsymbol{A}$ ) and a socially isolated ( $\boldsymbol{B}$ ) bird. Color shadings (blue and green) highlight stable song motifs. The intact and socially isolated birds exhibited song stability at approximately dph 110. The crystallized song pattern of the socially isolated bird is similar to that of the intact bird, except for a prolonged and variable syllable (green bracket). C, Examples of song development and syllable scatter plots (duration vs mean FM) in two early-deafened zebra finches. Orange shading highlights stable song motifs. D, Normalized K-L distance calculated from the last syllable scatter plot representing crystallized/stabilized song patterns. The values of $\mathrm{K}-\mathrm{L}$ distance at $\mathrm{dph} 45-59$ are normalized as 1.0. A value near 0 indicates a crystallized/stabilized song pattern. Mean \pm SEM (intact, $n=4$; socially isolated, $n=5$; earlydeafened, $n=6$; Student's $t$ test with Bonferroni's correction, ${ }^{* *} p<0.01$ )

criteria and were processed. Arrays were quantile normalized, and the fluorescence value was transformed to $\log _{2}$ scale.

ANOVA was used to identify probes differentially expressed between developmental stages in the intact birds $(p<0.05 ; 3362$ and 1466 probes in HVC and RA, respectively). The expression levels of these genes were compared between the intact and early-deafened birds to assess how auditory input influenced gene expression levels. Principal component analysis (PCA) using the prcomp package and three-dimensional view using the rgl package in $\mathrm{R}$ were used to visualize the separation of samples.

Weighted gene coexpression network analysis (WGCNA) was performed using the WGCNA R package for additional investigation of the relation between biological traits (age, audition status, and song characteristics) and clusters of coregulated genes (Langfelder and Horvath, 2008). General information about network analysis methodology and WGCNA software is available at http://labs.genetics.ucla. edu/horvath/htdocs/CoexpressionNetwork/. Differentially expressed probes ( 9903 and 6536 probes in HVC and RA, respectively) selected on the basis of a minimum 1.5-fold change and $p<0.05$ ( $t$ test) within a song nucleus were included. Pairwise Pearson's correlation coefficients were calculated for all genes selected. The resulting Pearson's correlation matrix was transformed into a matrix of connection strengths (an adjacency matrix) using a power function $\left.[(1+\text { correlation }) / 2)^{\beta}\right]$, which was then converted to a topological overlap matrix. WGCNA identifies modules of densely interconnected probes by hierarchical clustering based on topological overlap, a biologically meaningful measure of similarity of expression patterns among all pairs of probes across all treatment conditions and by assigning each probe to a "module" based on shared expression patterns. A preliminary network was built to assess overall connectivity. From this network, the 6500 and 3800 probes in HVC and RA, respectively, with the highest connectivity were retained for subsequent WGCNA. For analysis using all expressed probes, we first omitted the probes with low connectivity (whole-network connectivity; k.total $<0.5$ and gray module), and then 32,607 probes in HVC and 21,669 probes in RA were used in the network construction. Modules were defined as branches of the dendrogram obtained from clustering and were labeled by colors beneath the dendrograms. To study the relationship between expression variability within the modules and behavioral trait variability, correlations were computed between principal components of each module and traits. $p$ values were computed for each correlation.

\section{Results \\ Song development and stabilization in early-deafened songbirds}

To examine how a song developed and the characteristic song patterns under an audition-deprived condition, the male zebra finches were deafened by removing the cochleae before fledging (dph 18-22; average dph, $19 ; n=6$ ), a time during which no song production is observed, and song ontogeny was compared in the intact and socially isolated birds $(n=4$ and 5, respectively). Because of sensorineural hearing loss, the songbirds missed listening to song models and monitoring their own vocal outputs. These early-deafened birds showed slower song development than the intact and socially isolated birds. Clear differences in song development were observed at dph 140-180; during this period, the majority of the intact birds exhibited crystallized song patterns (Fig. $1 A, B, D$ ). In contrast, the early-deafened birds still generated variable song sequences with fewer harmonic syllables, resembling the early plastic songs recorded during early normal development. However, the deafened birds eventually exhibited stabilized song patterns characterized by stable temporal sequences of distinguishable syllables by approximately dph 300 , which is approximately three times longer than the time required for song crystallization in the intact birds (Fig. $1 C, D$ ). There was a significant difference in the degree of song stabilization between the early-deafened and intact birds at dph 140-180 (Student's $t$ test with Bonferroni's correction, $p<0.01$; Fig. $1 D$ ). Although there was no significant difference in the song stabilization trajectory between the socially isolated and early-deafened birds, the socially isolated birds exhibited a tendency for generating "parts" of a motif structure and stabilizing the acoustic features for the majority of syllables with a time course similar to that in the intact birds (Fig. $1 A, B$, syllable scatter plots). In contrast, all the earlydeafened birds continued to generate acoustically unstable syllables across bouts, and their stable motif patterns did not emerge 
after more than dph 300. The stabilized songs of the deafened birds were composed of a motif structure showing a variety of individual differences in the number of syllables, acoustic features, syllable durations, and intersyllabic intervals (Figs. 1C, 2A). These individual differences were observed even among siblings from the same family (Fig. 2A). During the developmental period before song crystallization/stabilization, circulating testosterone concentration and singing frequency were not significantly different between the intact and early-deafened birds (Fig. 2B,C). Furthermore, it was also observed that the early-deafened birds directed songs to females and exhibited normal mating behavior at approximately dph 100, the typical time of sexual maturity, suggesting that delayed song stabilization in the early-deafened birds did not generally reflect retardation in development. These results indicate that hearing loss at an early developmental stage delayed but did not prevent the eventual slow development of some stable syllables and structured vocal sequences.

\section{Activity of the basal ganglia-forebrain circuit during audition-independent song crystallization/stabilization}

We next set out to examine where auditory deprivation affects the neural circuits that mediate vocal learning and production and how it causes delayed song development and audition-independent song crystallization. The basal ganglia-forebrain circuit AFP is considered to contribute to the generation of vocal variability necessary for audition-dependent song plasticity (Kao et al., 2005; Ölveczky et al., 2005; Andalman and Fee, 2009). Lesions of the AFP output nucleus, lateral magnocellular nucleus of the anterior nidopallium (LMAN), and basal ganglia nuclei Area X prevent song deterioration induced by auditory deprivation at the adult stage (Brainard and Doupe, 2000; Kojima et al., 2013). In addition, the pharmacological inactivation of LMAN dramatically reduces the acoustic and sequence variability of songs at the juvenile stage (Ölveczky et al., 2005). Based on these observations, we hypothesized that abnormally increased or decreased activity of the AFP nuclei during song development delays song development and stabilization in the early-deafened birds. To test these possibilities, we compared the neural activity of AFP among the juvenile (dph 47-59; mean \pm SEM, dph $55.17 \pm 0.58$ ), young adult (dph 102147; mean \pm SEM, dph $133.16 \pm 3.89$ ), and older adult (dph 327-1715; mean \pm SEM, dph 881.06 \pm 67.24) birds (both intact and early-deafened) using two approaches: (1) molecular map-
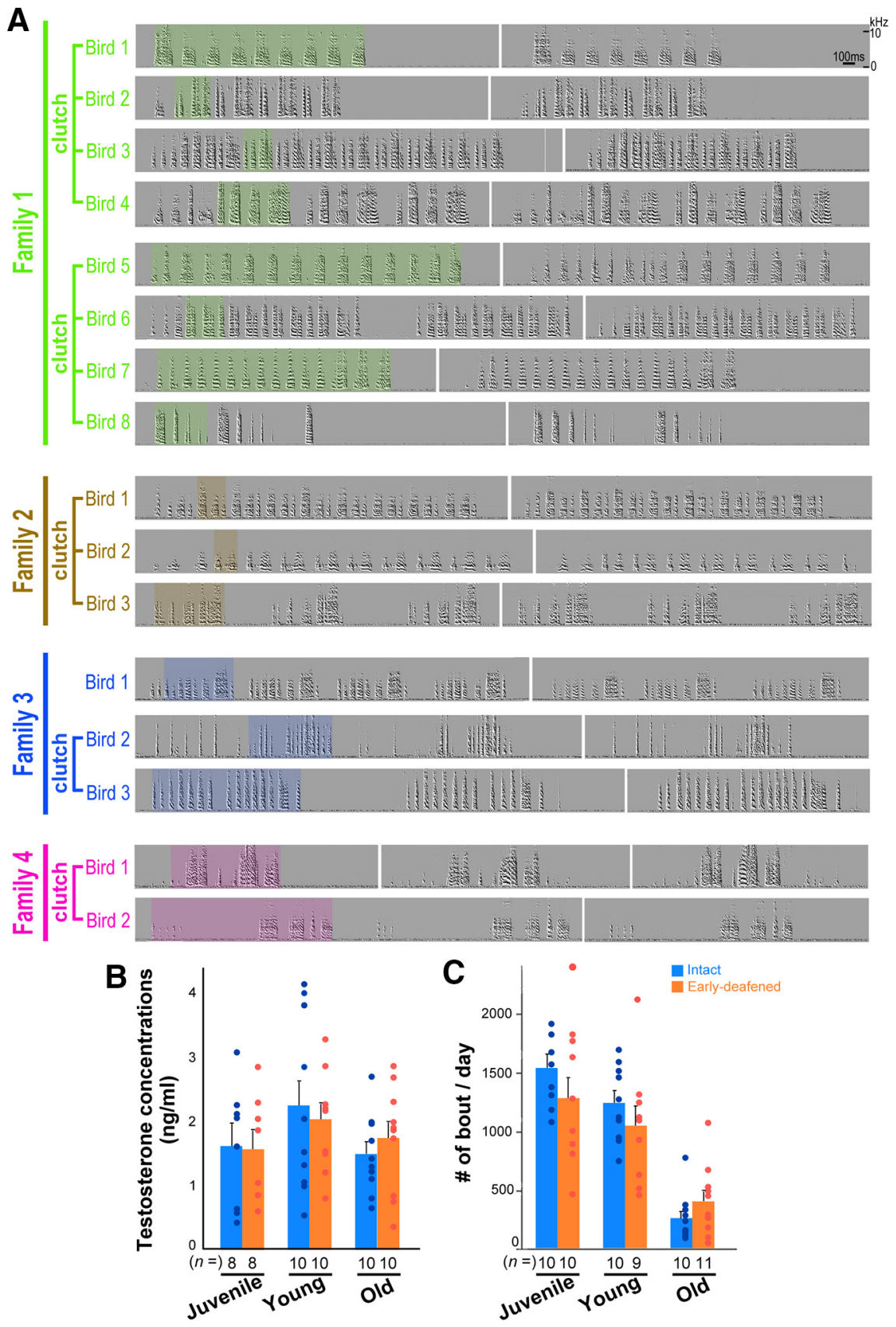

Figure 2. Individual differences in stabilized song patterns in early-deafened zebra finches. $\boldsymbol{A}$, Zebra finches deafened at dph $18-22$ developed unique song patterns with a characteristic motif-like structure (colored shadings) at the old adult stage (older than dph 300). Sixteen early-deafened birds from four families are indicated. $\boldsymbol{B}$, Average levels of circulating testosterone at three developmental stages, juvenile (dph 50-60), young (dph 105-130), and old (older than dph 330), in the intact (blue bars) and early-deafened (orange bars) birds. No significant difference was observed in serum testosterone between the two groups at any developmental stage. Each dot and bar represents individual values and mean \pm SEM, respectively, of testosterone concentrations (nanograms per milliliter). Each animal number is indicated under the bar. C, Average number of song bouts per day during the three developmental periods, juvenile (dph 60 - 65), young (dph 100 - 110), and old adult (dph 440 -920), in the intact (blue bars) and early-deafened (orange bars) zebra finches. Comparison of the intact and early-deafened birds indicates no significant difference at each stage (juvenile, $p=0.236$; young, $p=0.352 ; 0$ ld, $p=0.237$; Student's $t$ test). Each dot and bar represents individual values and the mean $\pm S E M$, respectively. Each animal number is indicated under the bar.

ping analysis of activity-induced genes (Wada et al., 2006; Horita et al., 2012); and (2) behavioral analysis of vocal outputs driven by AFP (Aronov et al., 2008). The neural activity-induced genes Dusp 1 and c-fos were used as molecular markers of AFP activity because both were induced by singing in all three AFP song nuclei: LMAN, striatum nucleus Area X, and dorsal lateral nucleus 


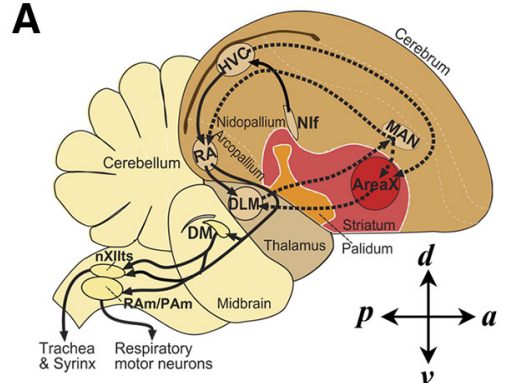

B
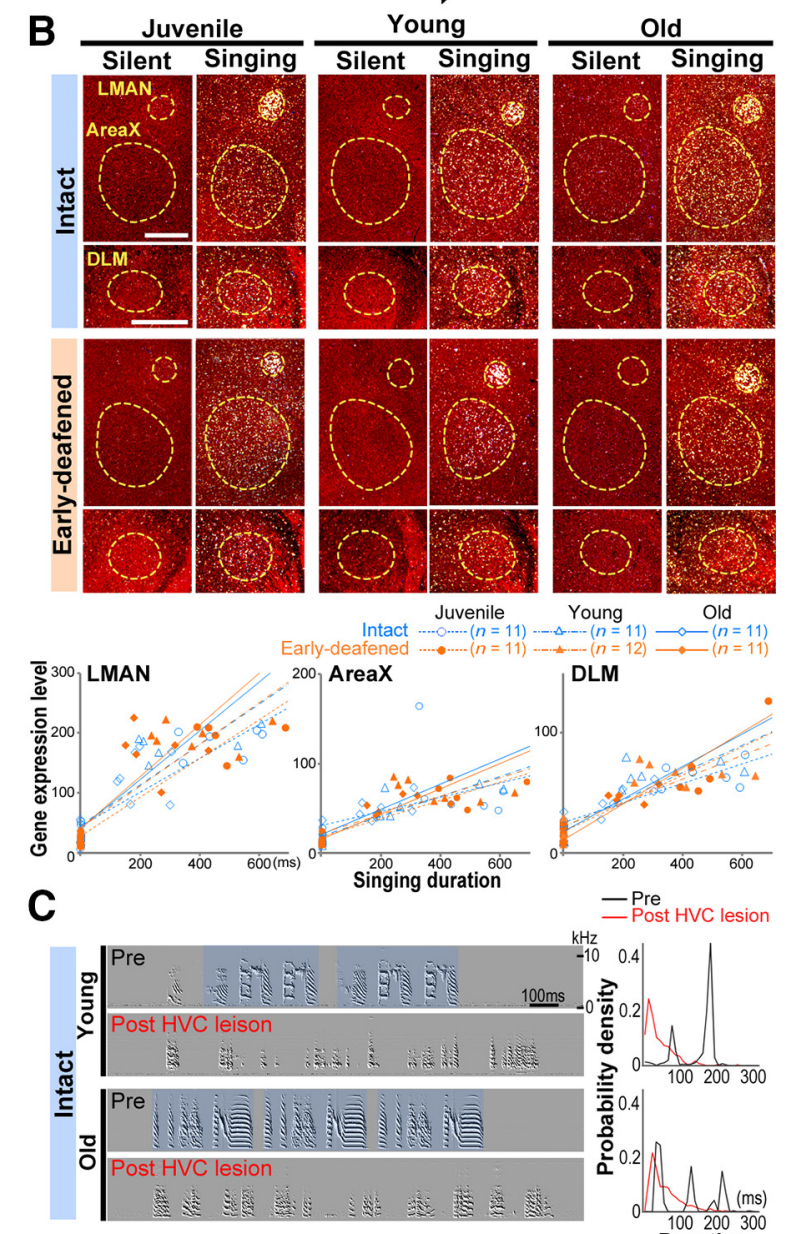

c
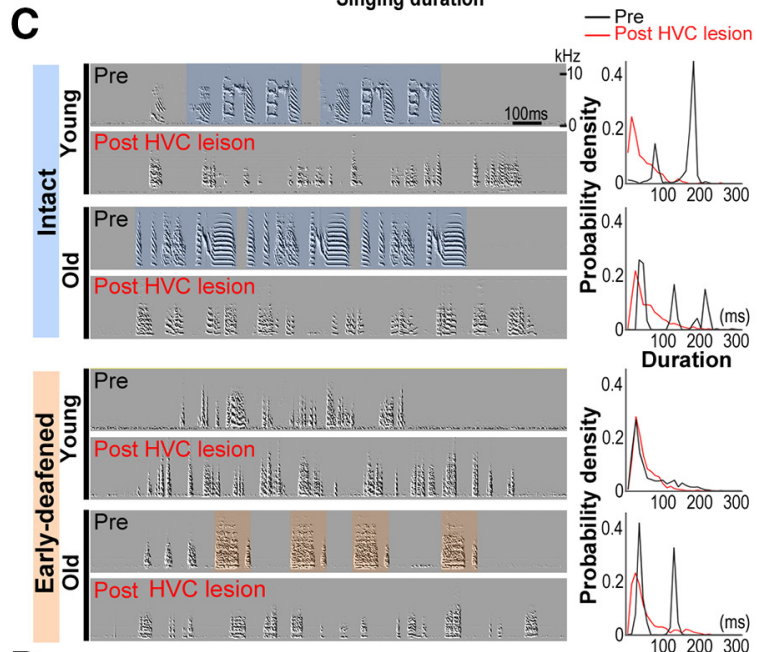

D
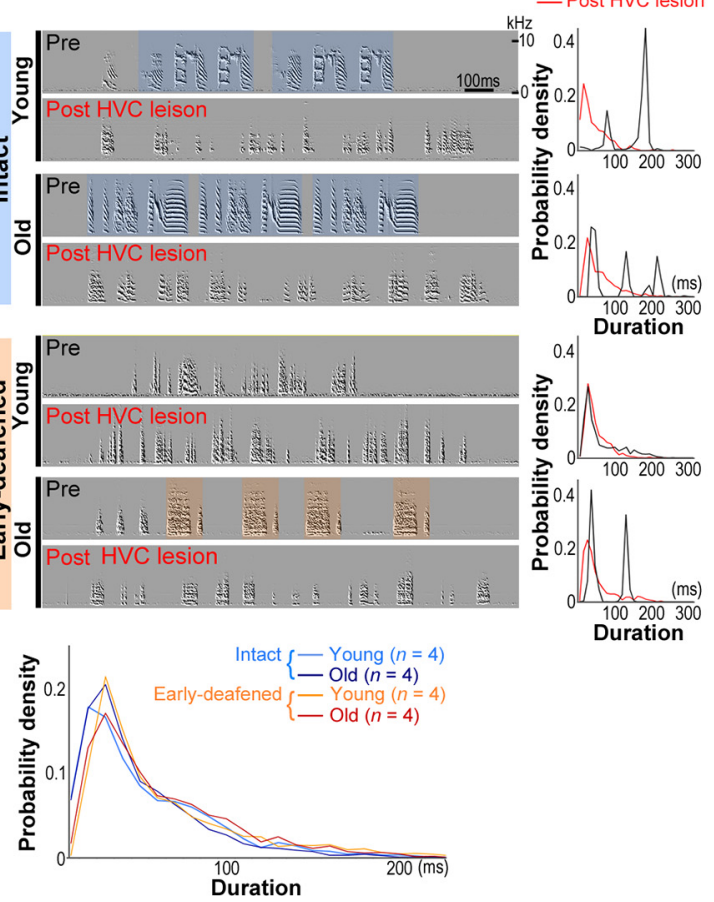

Figure 3. Similar induction of neural activity-induced gene expression and vocal output from the basal ganglia-forebrain circuit (AFP) before and after song crystallization/stabilization. $\boldsymbol{A}$, Diagram of brain song circuits. Black solid lines denote connections within the posterior vocal motor circuit and black dashed lines within the basal ganglia-forebrain circuit AFP. of the medial thalamus (DLM) (Fig. 3A). There were no significant differences in singing-induced expression levels of Duspl in the same nuclei between the age-matched early-deafened and intact birds (Fig. 3B). The consistent result was also observed with the c-fos probe (data not shown). Furthermore, after bilateral lesions of the premotor nucleus HVC, both the intact and earlydeafened birds at the young and adult stages exhibited highly similar AFP-driven vocal outputs with coincident syllable duration distributions (Fig. 3C,D). These results suggest that molecular signaling cascades in the AFP nuclei and AFP-driven premotor outputs are similarly regulated regardless of age or the presence of auditory inputs.

\section{Audition-dependent sensitivity and audition-independent robustness of gene expression dynamics in the motor circuit during song development}

Because we observed unaltered AFP activity throughout song development in both the intact and deafened birds, we considered the possibility that the autonomous changes associated with song development regulation and crystallization timing exist in the vocal motor output circuit. A decrease in vocal variability has been attributed to the strengthening of inputs from HVC and the concurrent weakening of inputs from LMAN to RA at the synaptic level (Herrmann and Arnold, 1991; Stark and Perkel, 1999). Furthermore, HVC is the only song system nucleus that receives direct projections from auditory areas (Bauer et al., 2008). Adult deafening reduces the size of dendritic spines and alters spontaneous action potential activity in HVC projection neurons to Area X (Tschida and Mooney, 2012). Therefore, HVC and RA might be affected by audition deprivation and delayed vocal development. In addition, several studies have indicated a relationship between song development and gene expression changes in the motor circuit (Soderstrom and Tian, 2006; Wada et al., 2006; Balmer et al., 2009; Matsunaga et al., 2011). Thus, we first examined the induction level of Egrl (Zenk), a neural activity-induced and neural plasticity-related gene (Jones et al., 2001), that was shown previously to be more highly induced by singing in the motor nucleus RA of juveniles compared with that of adult birds (Jin and Clayton, 1997b). As reported previously, Egrl expression in the RA was significantly higher after singing during the juvenile plastic song phase (dph $47-59$ ) than that during young adult

\footnotetext{
$\leftarrow$

$B$, Singing-driven Dusp 1 mRNA expression in the AFP song nuclei, LMAN, Area X, and DLM in the intact and early-deafened zebra finches at juvenile (dph 47-59), young (dph 102-147), and old (dph 327-1715) stages. The young stage is pre-song stabilization stage for the early-deafened finches and post-stabilization for the intact finches. The old stage is post-stabilization for the early-deafened finches. White and red represent the Dusp1 mRNA signal and Nissl counterstained cells, respectively, in sagittal brain sections (right, anterior; up, dorsal). Scale bar, $1 \mathrm{~mm}$. Summarized graphs show the relationship between total singing duration and Dusp 1 gene expression level in LMAN, Area X, and DLM. There is little difference in this relationship between the intact and early-deafened songbirds at all three developmental stages (LMAN, $p=0.83$; Area $\mathrm{X}, p=0.36 ; \mathrm{DLM}, p=0.11$; regression analysis). Each dot represents individual values; the regression line is indicated for each group (intact, blue; early-deafened, orange; juveniles, circles; young adults, triangle; old adults, diamonds). C, Example of similar vocal outputs after HVC lesion (producing AFP-driven songs) at young and old adult stages in both the intact and early-deafened zebra finches. Characteristic motif-like structures are shaded. Changes in song patterns (left) and distributions of syllable durations (right) before and after HVC lesion (black and red lines, respectively). $\boldsymbol{D}$, Average probability density distribution of syllable duration for AFP-driven songs after HVC lesion (light blue, young intact bird at dph 115-138; blue, old intact bird at dph 660-1746; orange, young early-deafened songbird at dph 108-159; and red, old early-deafened songbird at dph 549-1037). d, Dorsal; a, anterior; p, posterior; v, ventral; NIf, interfacial nucleus of the nidopallium; RAm/PAm, nuclei retroambiguus and paraambiguus; nXIlts, 12th nucleus, tracheosyringeal part.
} 


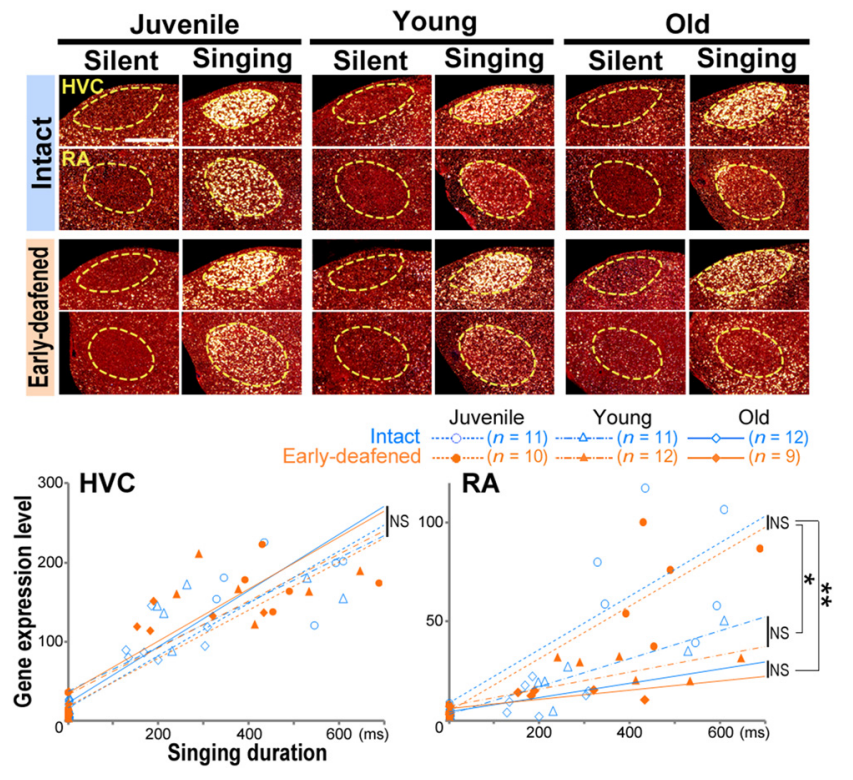

Figure 4. Developmental regulation of singing-induced Egr1 expression in the motor circuit among intact and early-deafened zebra finches. In contrast to HVC, induction of Egr1 mRNA expression is differentially regulated through development in RA, i.e., higher in the juvenile (dph 47-59) than in the young (dph 102-147) and old (dph 327-1715) adult stages for both the intact and early-deafened birds (HVC, $p=0.55 ; \mathrm{RA}^{*} p=0.0232$ for juvenile vs young; ${ }^{* *} p=0.0017$ for juvenile vs old, regression analysis). However, there is no significant difference in the induction rate of Egr1 among the developmental stage-matched intact and earlydeafened groups in HVC and RA (juvenile, $p=0.6024$; young, $p=0.7451$; old, $p=0.8153$ for the intact vs early-deafened birds in $\mathrm{RA}$, regression analysis). Each dot represents individual values; the regression line is indicated for each group (intact, blue; early-deafened, orange; juveniles, circles; young adults, triangle; old adults, diamonds). White and red represent Egr 1 mRNA signal and Nissl counterstained cells, respectively, in sagittal brain section (right, anterior; up, dorsal). Scale bar, $1 \mathrm{~mm}$.

(dph 104-147) or older adult (dph 327-1715) crystallized song phases in the intact birds (regression analysis, $p<0.05$; Fig. 4 ). In addition, in the early-deafened zebra finches, Egr1 expression dynamics in the motor nuclei HVC and RA were very similar to the intact birds, although the intact and early-deafened birds developed individual song patterns at different rates (Fig. 4), suggesting that expression of neural plasticity-related genes during development is not substantially altered by auditory input.

This result of Egrl expression motivated us to conduct global transcriptome analysis in both the intact and early-deafened zebra finches because acquisition of complex song pattern should be achieved by orchestral contribution of a large variety of genes and not by a few restricted numbers of genes. Thus, we used a strategy to evaluate gene expression dynamics in the motor circuit nuclei, HVC and RA, during the critical period of vocal learning in both the intact and early-deafened birds. Global transcriptome profiling was performed using the total RNA extracted from the laser microdissected HVC and RA at three developmental stages: (1) juvenile, dph 54-57; (2) young adult, dph 121-135; and (3) older adult, dph 504-787 $(n=3$ deafened and intact birds at each developmental stage). We used the songbird oligoDNA array platform for comprehensive coverage of genes expressed in the zebra finch brain (Warren et al., 2010). After quality-control assessment and normalization (see Materials and Methods), we surveyed 41,525 probes (11,391 gene-symbol identified genes) in HVC and 41,340 probes (11,374 genes) in RA of the 43,552 probe total set during at least one developmental period. We identified 3362 probes in HVC (2120 genes, $8.10 \%$ of the total HVC-expressed probes) and 1466 probes in RA (974 genes, 3.54\% of the total RA-expressed probes) that were differentially expressed during at least one developmental period (ANOVA, $p<0.05$; Fig. 5A). These developmentally regulated genes encoded signal transduction proteins, receptors, ion channels, cell adhesion molecules, neuron differentiation factors, and neuronal transcription factors, including Sox4, Hey1, Znf238, Neurod6, and Mxil (Fig. 5B). In the early-deafened birds, there were many fewer significant differences in expression between developmental periods in both HVC [ 1922 of 2120 genes: 2959 of 3362 probes (88.0\%)] and RA [915 of 974 genes: 1357 of 1466 probes $(92.6 \%)$ ]. In contrast, individual variability in expression was much higher as evidenced by the larger CV in the earlydeafened birds compared with the intact birds (Fig. $5 A, C$ ). This finding suggests that an underlying genetic program of developmental neural maturation continues after deafening, with auditory experience driving the stabilization of gene expression patterns and levels. Nonetheless, examination of gene expression heat maps (Fig. 5A) showed similar gene expression patterns between groups and preservation of age-dependent expression dynamics in the early-deafened birds. Nearly all genes [2120 genes in HVC (100\%) and 973 genes in RA (99.9\%)] showed qualitatively similar intrinsic expression patterns during development, indicating the audition-independent robustness of gene expression dynamics in the motor circuit during song development. This robustness of gene expression dynamics is also indicated by similar regulation of average of expression levels for most genes between the intact and early-deafened birds at each developmental stage (Fig. 5C).

Moreover, the audition-independent robustness of agedependent gene expression dynamics in the motor circuit could be demonstrated using the same set of genes (3362 and 1466 probes in HVC and RA, respectively) by applying PCA. We reduced the dimensionality of the gene expression pattern distribution by applying PCA to the collection of feature distributions of the intact and early-deafened birds at three developmental stages (juvenile, young adult, and older adult), and the first three principal components (PC1, PC2, and PC3) were used to obtain the three-dimensional gene expression values. The principal components for gene expression values showed separable clusters for the three developmental stages but not for audition $(+/-)$ in both HVC and RA (Fig. 5D). The core of each cluster was composed of intact individuals within the same age group surrounded by the age-matched early-deafened individuals, indicating auditionindependent, age-driven robust stability of gene expression programs but audition-dependent sensitivity that reduced expression fluctuation in the presence of auditory feedback.

To extract additional information on gene expression dynamics from the transcriptome dataset linked to developmental stage (age), audition $(+/-)$, and song phenotype, we performed WGCNA (Zhang and Horvath, 2005; Hilliard et al., 2012), which allows for the identification of "gene modules" of coexpressed genes. Similar to PCA, WGCNA can also overcome a potential problem associated with the small sample size of the DNA microarray experiment because three developmental datasets were combined in both the intact and deafened groups and used as a single dataset for the analysis $(n=18$ in HVC and RA, separately). Within a set of genes that were differentially expressed to a significant level during at least one developmental stage in both the intact and deafened birds (6500 probes including 3744 genesymbol identified genes for HVC and 3800 probes including 2379 genes for RA), we identified seven modules of coexpressed genes in HVC and nine in RA (Fig. 6). All gene modules in HVC (4662 probes, 2874 known genes) and four of nine modules in RA (1664 
A
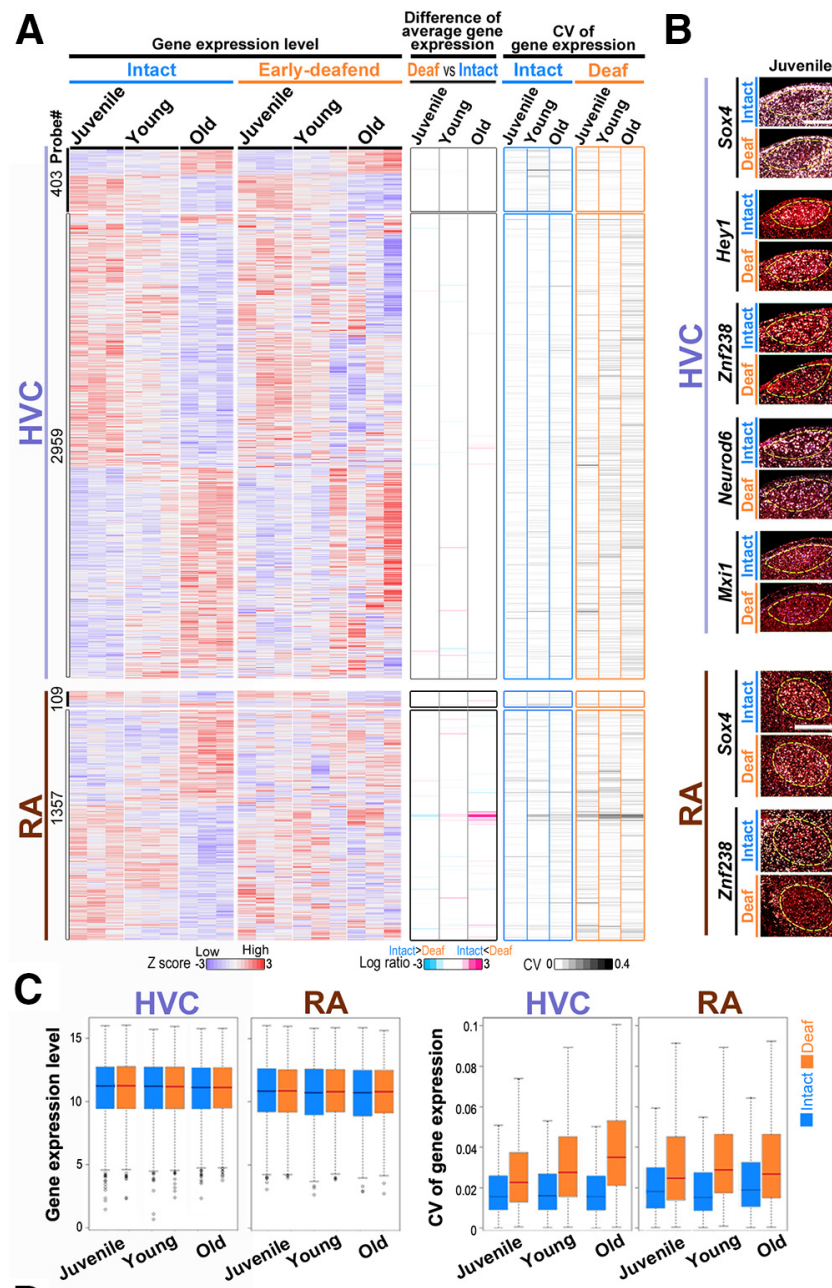

D

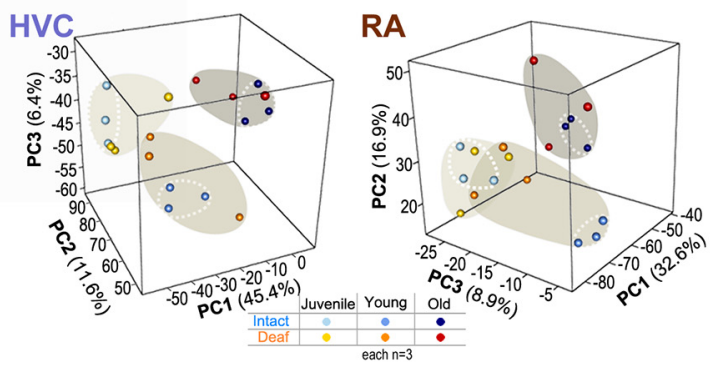

Figure 5. Gene expression dynamics in the motor circuit nuclei HVC and RA during development in intact and early-deafened zebra finches. $A$, Left, heat maps; expression levels of 3362 and 1466 gene probes in HVC and RA, respectively, with significant differences across developmental stages in the intact zebra finches (ANOVA, $p<0.05$ ). The greater the absolute value of the $Z$ score, the greater the deprivation of the expression of the gene from the mean, which indicates the significance of change in expression. Expression of the majority of these gene probes (2959 in HVC and 1357 in RA, white vertical bars) were not significantly different at the aged-matched developmental stages between the intact and early-deafened birds (ANOVA, $p<0.05$ ), indicating that the gene expression dynamics of the early-deafened songbirds qualitatively has a similar trend to those of the intact songbirds through developmental stages. Middle column, Differences in average gene expression level between the intact and deafened birds at age-matched stages. Right columns, CV of gene expression level for each gene probe at each developmental stage in the intact and early-deafened birds. $\boldsymbol{B}$, mRNA expression levels of the differentially regulated transcription factors Sox4, Hey 1, Znf238, Neurod6, and Mxi in HVC and RA at three developmental stages for the intact and early-deafened songbirds (juvenile, dph 47-59; young, dph 104-146; and old adult, dph 332-1715). White and red represent mRNA signal and Nissl counterstained cells, respectively, in the sagittal brain section (right, anterior; up, dorsal). Scale bar, $1 \mathrm{~mm}$. In the intact birds, all genes examined were differentially regulated during development $\left({ }^{*} p<0.05\right.$ after Bonferroni's correction). In contrast, Znf238, Neurod6, and Mxi1 expression levels were not significantly different between stages in the early-deafened songbirds. Summarized bar graphs show the average gene expression level in each group (each animal number is indicated by inside bars). Each dot represents individual values (intact, blue; early-deafened, orange). C, Gene expression level (left) and CV of gene expression (right) in HVC and RA at juvenile, young, and old adult stages in the intact (blue) and early-deafened (orange) birds, using the same set of gene probes as shown in $\boldsymbol{A}$. Each box illustrates median and interquartile range. $\boldsymbol{D}$, Gene expression dynamics in HVC and RA calculated by PCA using the same set of gene probes as shown in $\boldsymbol{A}$. Beige shading indicates age-matched intact (light blue, blue, and dark blue) and early-deafened (yellow, orange, and red) groups. The darker color indicates the older group. probes, 1097 known genes) significantly correlated with the age-related parameters: days post-hatching and developmental stage. After Bonferroni's correction, the first principal components of modules 1 and 2 in HVC (Fig. 6, turquoise and blue, respectively) were significantly related to age and motif consistency. The positive correlations of module 1 (2620 probes representing 1752 genes) in HVC indicate upregulation of gene members during development. In contrast, module 2 (2295 probes representing 1353 genes) in HVC indicates a strongly negative correlation to age and thus represents downregulation of gene members during development. Module 1 (Fig. 6, turquoise, 1162 probes representing 816 genes) and module 3 (Fig. 6, brown, 736 probes representing 496 genes) in RA also indicate significantly positive and negative correlations to age, respectively. Some of the gene modules, such as 1 and 2 in $\mathrm{HVC}$ and 7 in RA (Fig. 6, black), also have weak but significant correlations with song parameters related to temporal regulation and syllable phonology. However, no gene module in either HVC or RA showed any significant correlation with auditory input. Likewise, no gene modules exhibited any significant correlation with auditory input in either HVC or RA when the data were reanalyzed using all expressed genes for WGCNA (using 41,525 and 41,340 probes for HVC and RA, respectively) instead of only the developmentally regulated subset. These results indicate the existence of audition-independent gene expression programs in the vocal motor circuit during song development at the coexpression network level.

\section{Audition-independent gene expression} dynamics associated with inevitable termination of vocal plasticity and acquisition of structured song patterns The above results indicate a discrepancy between song phenotype variation and stable gene expression dynamics in the vocal motor circuit during development in the absence of auditory input. Song crystallization/stabilization, typically observed at the young adult stage (dph $100-$ 120 ) in the intact birds, was still observed in the early-deafened birds but at older ages (older than dph 300). However, the global gene expression pattern and level in the vocal motor circuit nuclei were quite similar between the age-matched intact and deafened birds and were clearly different among the three developmental stages within these two groups. Thus, the gene expression pattern observed at the 


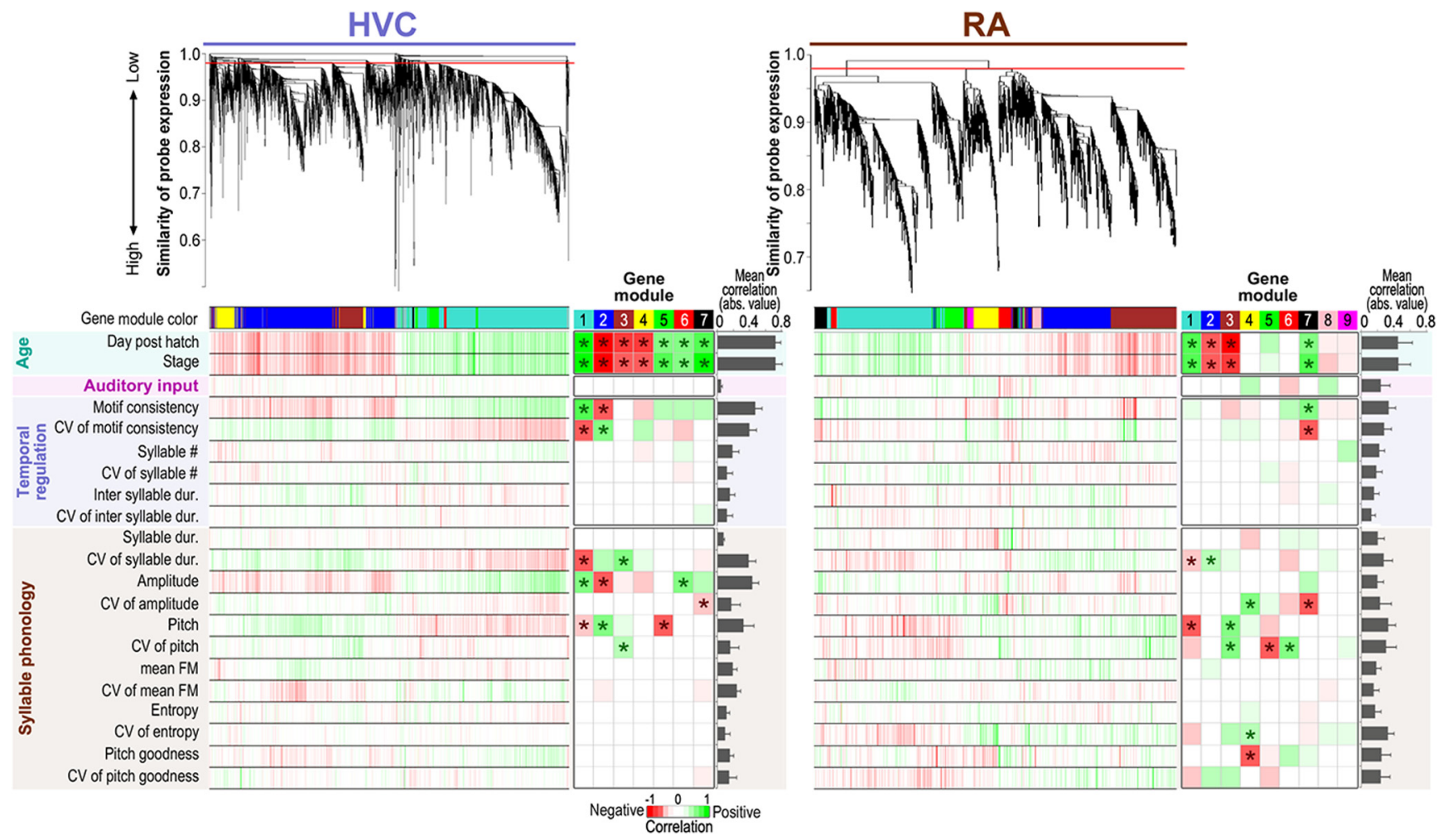

Figure 6. Gene coexpression network analysis reveals strong correlations between gene modules and age-related factors but not with auditory input. Top, Dendrogram produced by average linkage hierarchical clustering of gene probes identifies seven and nine modules of coexpressed genes in HVC and RA, respectively. The red lines in the dendrograms indicate the height at which the tree was cut. Colored blocks denote individual gene modules. Bottom, Correlation between gene modules and age-, auditory input-, temporal regulation-, and syllable phonology-related parameters. Colored bands indicate positive (green) and negative (red) correlations. For each module (columns), heat maps show correlations to measured parameters (rows). Asterisks in each cell indicate significant trait relationships ( $p<0.05$, Student's asymptotic $p$ values), for example, all seven gene modules in HVC and four gene modules (modules $1,2,3$, and 7) in RA significantly correlate with the age-related parameters. Bar plots show average strength of module correlations to measured parameters (mean $\pm 95 \%$ confidence intervals).

older adult stage (older than dph 300) in both the intact and deafened birds may be a molecular signature representing the "absolute" endpoint of vocal plasticity associated with auditionindependent vocal crystallization/stabilization. To examine this idea, we analyzed the long-term song stability after deafening after song pattern crystallization. Deafening young adult zebra finches induces deterioration of crystallized song patterns and results in variable song patterns (Nordeen and Nordeen, 1992; Lombardino and Nottebohm, 2000; Horita et al., 2008). This deterioration and instability of song pattern by adult auditory deprivation is considered to be the result of an output signal from the basal ganglia-forebrain circuit AFP, which detects mismatching of auditory feedback and vocal outputs, to the vocal motor circuit (Brainard and Doupe, 2000). However, instead of focusing on song deterioration, we examined whether unstable and variable song patterns continued or some degree of structured song pattern was eventually reattained because of an inherent decrease in vocal plasticity (i.e., if there is an age beyond which significant vocal plasticity cannot occur). We observed song deterioration and increased variability in song patterns 1 month after deafening in young adult birds $(n=4$ at deafening operations were performed at dph 105-157; average dph, 123.5). However, by dph 300-400, vocal variability started to decrease and the song restabilized with a motif structure (Fig. 7). The restabilized song was distinctly different from the first crystallized song pattern and showed unique motif structure across birds (Fig. 7A). Individual song patterns, once stabilized, were repeatedly generated with the same temporal pattern and sequence and phono- logically deteriorated to stable syllables, resembling the songs of the early-deafened birds.

Using a set of transcription factors that showed developmentally different regulation in the motor circuit nuclei HVC and RA (Fig. 5B), we examined the gene expression patterns and levels in the young adult-deafened birds during the song deterioration ( $>1$ week after deafening, $n=5$ at dph 104-161; average dph, 132.4) and recrystallization phases $(n=6$ at dph 1158-1551; average dph, 1274). We then compared these patterns with those of the age-matched intact and early-deafened birds; however, no significant differences in gene expression were observed in HVC and RA for any transcription factor examined among all the age-matched intact, early-deafened, and young adult deafened groups (Fig. 7C). These results supported the idea of a genetic program-associated "absolute" end of vocal plasticity.

\section{Discussion}

Sensorimotor development is accelerated during critical periods of behavioral variation corresponding to enhanced neuroplasticity, followed by behavioral stabilization concomitant with reduced neuroplasticity. However, a certain degree of development and complex motor behavior may be achieved without the appropriate sensory inputs and may be driven by intrinsic developmental genetic programs instead. Our study revealed auditionindependent vocal development and stabilization in a songbird zebra finch. Neural activity-dependent gene induction and vocal output driven by the AFP was similar throughout development in both the intact and deafened birds. Although our global tran- 

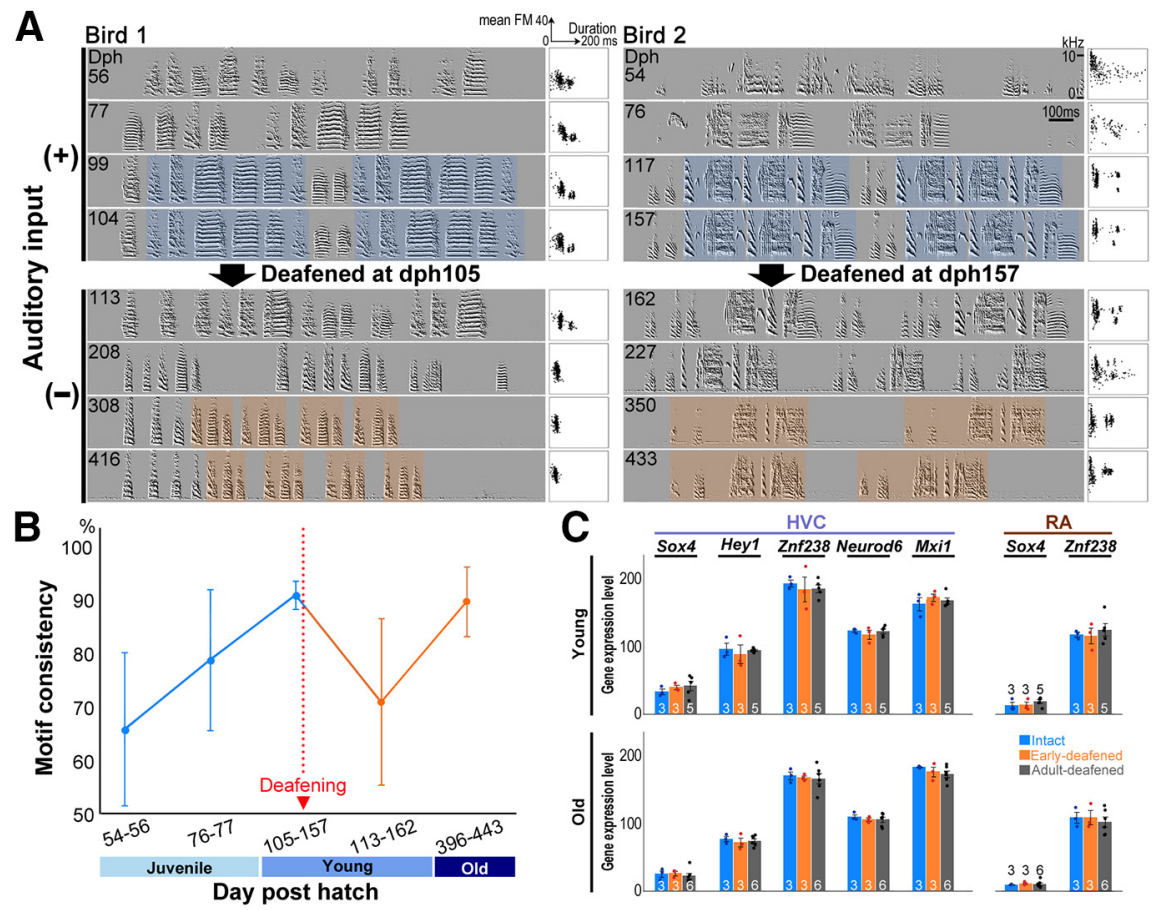

Figure 7. Zebra finches deprived of auditory input after song crystallization restabilize their song at the old adult stage after deafening-induced song deterioration. $\boldsymbol{A}$, Spectrograms of two example birds show song before and after adult deafening. Songs restabilize without auditory input at the old adult stage (orange shading in the bottom panels), i.e., the same period when early-deafened birds stabilize their song. Blue shading indicates that the first crystallized songs developed at dph 100-150, with audition appearing before adult deafening. $\boldsymbol{B}$, Change of motif consistency at each experimental stage before and after adult deafening (blue and orange spots, respectively; $n=4$, mean \pm SD). Motif consistency was calculated as the song similarity among 20 song motifs that were randomly selected at each developmental time point in each bird. $\boldsymbol{C}$, mRNA expression levels of the developmentally regulated transcription factors Sox4, Hey1, Znf238, Neurod6, and Mxi1 in HVC and RA at two developmental stages for the intact, early-deafened, and young adult-deafened songbirds (young, dph 104-161; old adult, dph 1158-1551). Young adult-deafened operations were performed at dph 92-144. No significant difference was observed for any gene among the three groups at both stages (ANOVA, $p>0.05$ ). Bar graphs show average the gene expression level in each group (each animal number is indicated by inside bars). Each dot represents individual value (intact, blue; early-deafened, orange; and young adultdeafened, black).

scriptome analysis identified $>3000$ genes differentially regulated in the vocal motor circuit during normal song development, we also observed similar qualitative patterns of developmental gene expression between the hearing-intact and early-deafened birds using PCA and WGCNA. Thus, vocal motor circuit maturation was driven by an audition-independent genetic mechanism. However, we cannot rule out the possibility that discrete effects of deafening on gene expression could be detected using other experimental designs (e.g., larger sample sizes, testing during singing instead of silence, testing at other developmental time points, or testing the AFP song nuclei). Adult deafening reduces the size of dendritic spines and alters spontaneous action potential activity only in Area X projection neurons of HVC (Tschida and Mooney, 2012). Therefore, audition deprivation could alter developmental gene expression in a cell type-specific manner.

A few studies have examined the regulation of neural plasticity-related gene expression in the song system in social isolation-reared songbirds (Jin and Clayton, 1997a; Sakaguchi, 2004); however, to the best of our knowledge, the present study is the first to examine the dynamics of the brain transcriptome in a vocal learner under audition deprivation, a crucial epigenetic factor in vocal learning. It has been reported that several genes associated with song development are expressed in the song system during the critical period of song learning in audition-intact birds
(Soderstrom and Tian, 2006; Balmer et al., 2009; Kubikova et al., 2010). In addition, gene manipulation and pharmacological studies of motor circuit genes regulated by development reflect the effects on song development and song pattern generation (Denisenko-Nehrbass et al., 2000; Matsunaga et al., 2011). However, our global transcriptome analysis revealed a discrepancy between the dynamics of gene expression and song ontogeny, particularly during the young adult stage, when gene expression patterns were similar between the intact and deafened birds, but the stability of their song patterns differed considerably. Moreover, during the critical period, singing-driven gene expression of Dusp1, c-fos, and Egrl was unaltered in the absence of audition input in both AFP and motor circuits, even with long-term auditory deprivation. A large set of neural plasticity-related genes in song nuclei are regulated by singing (Li et al., 2000; Poopatanapong et al., 2006; Wada et al., 2006), which suggests that singing-driven gene expression is also regulated purely by motor activity and not sensory information (hearing input; Teramitsu et al., 2010). Therefore, volitional singing itself (and/or total amount of singing) as a motor activity could be a crucial developmental epigenetic factor that activates the genetic programs to regulate vocal plasticity and develop speciesspecific vocal patterns, just as the potency of the external environment provides experience-dependent stimulation that regulates the critical periods and neural plasticity of sensory-related circuits (Hensch, 2004; Knudsen, 2004). Recently, it was shown that both neural plasticity-related genes and epigenetic regulators are induced by neural activity. The direct epigenetic regulators, a DNA demethylation regulator Gadd45b (Ma et al., 2009) and a replacement histone H3.3b (Michod et al., 2012), are induced by singing-driven neural activation in song nuclei in both intact and deafened birds (Wada et al., 2006; our unpublished data). Although the data indicating direct relationships between motor-driven epigenetic regulation and developmentally regulated gene expression dynamics are still limited, neural activity-dependent modification of the DNA methylation landscape and subsequent gene expression changes have been demonstrated in the adult brain (Guo et al., 2011a,b). Therefore, audition-independent genetic programs in the song system may be directly or indirectly regulated by activation of the singing (motor)-dependent epigenetic factors. This idea fits with the observation that the intact and early-deafened birds exhibited a similar amount of singing during development (Fig. 2C), which can be examined by an experiment that includes long-term singing inhibition during the critical period of vocal learning, which might determine whether singing-inhibited songbirds showed delayed gene expression dynamics in song circuits.

How do early-deafened birds develop their songs and finally crystallize song patterns without a tutor song and their vocal feedback information? Although collateral afferent feedback 
from the syrinx and/or respiratory organs may guide neural maturation and song formation in a deafened condition, the AFP has been considered to generate the vocal exploration necessary for audition-dependent song learning to match with a tutor song (Andalman and Fee, 2009; Charlesworth et al., 2012). Therefore, it is speculated that the early-deafened birds continue random exploration of vocal outputs in their life. However, this supposed exploration of vocal outputs was not observed at the old adult stage even if the AFP is active while singing (Figs. $1 C, 3 C$ ). Song development of the early-deafened birds is delayed, but their song patterns were eventually stabilized. Similarly, songbird pupils do not continue to generate variable vocal outputs until they match the tutor song. Instead, they generate unique song patterns as their crystallized songs when they mature (Tchernichovski and Nottebohm, 1998). These facts suggest that the transfer of functional dominance from the AFP to the motor circuit is crucial for regulating vocal plasticity and stabilization, and this transference would persist under audition deprivation. Song patterns with species-specific song archetype were eventually crystallized in both the birds deafened before song development and the adultdeafened birds (Figs. 1, 7). These results indicate that the inherent endpoint for song stabilization was regulated by audition- and AFP-independent ways and further suggest the existence of intrinsic neural mechanisms for developing song phenotypes with species constraints and diversification.

Based on our finding regarding audition-independent gene expression dynamics and the similar crystallization and recrystallization timings of song of both the early- and adult-deafened birds, we propose a "two modes hypothesis" with "active" and "passive" modes that explains how song crystallization is regulated. Active song crystallization is considered the traditional song crystallization maintained by the AFP using auditory feedback. In the zebra finch, this active crystallization is usually observed at approximately dph 90-120. Although an outward song pattern of a young adult appears stable after song crystallization, the global gene expression patterns in the song circuits sustain a level of neural plasticity that allows changes in vocal patterns at syllable, phonological, and sequential levels. Therefore, the neural plasticity associated with active crystallization was revealed by manipulating auditory feedback, such as the delayed auditory feedback (Leonardo and Konishi, 1999) and deafening at the young adult stage in an AFP-dependent manner (Brainard and Doupe, 2000; Fig. 7). Furthermore, the neural plasticity associated with intrinsic gene expression patterns in a young adult would allow variable song patterns, with intervention of the AFP vocal exploration but without evaluation of auditory feedback. An active crystallized song may contribute to mating for young adults because it acts as an early deceptive sign of individual maturation, just as the female-directed song is more stable than the undirected song and is therefore considered more attractive (Woolley and Doupe, 2008). In contrast, late passive song crystallization would be independent of audition but associated with age and/or singing experience, which emerges in the zebra finch at approximately dph 300 . A previous experiment using adultdeafened zebra finches with a wide range of ages revealed a song deterioration that was more rapid in younger adults, whereas later-deafened adults showed few long-term changes in song structure (Lombardino and Nottebohm, 2000). The early- and adult-deafened birds revealed song stabilization and restabilization at approximately dph 300 (Figs. 1, 7). Furthermore, developmentally regulated gene expression patterns are similarly maintained in HVC and RA among the age-matched intact, early-deafened, and adult-deafened birds (Figs. 5, 7). These re- sults indicate the existence of an age-associated and/or singing experience-associated passive crystallization driven by auditionindependent gene expression dynamics in the vocal motor circuit. Although several deafening experiments have been performed in many songbird species, little attention has been paid to the timing of song crystallization and stabilization after auditory deprivation. Therefore, the existence of active and passive crystallization in other species remains to be examined, particularly in open-ended learners such as canaries that can learn new songs.

There is no doubt about the importance of genomic information as the molecular basis for gene expression dynamics in acquiring species-specific vocal patterns. Although it is crucial to use auditory information to control song development, auditory input is not the main driver of developmental gene expression dynamics in the motor circuit nuclei associated with auditionindependent vocal crystallization in the zebra finch. Therefore, the audition-independent gene expression dynamics would provide a molecular signature for revealing an intrinsic state of neural plasticity in the song system. However, it remains necessary to examine the possible contribution of neural activity-driven epigenetic regulation of vocal development and the critical period in vocal learners.

\section{References}

Andalman AS, Fee MS (2009) A basal ganglia-forebrain circuit in the songbird biases motor output to avoid vocal errors. Proc Natl Acad Sci U S A 106:12518-12523. CrossRef Medline

Aronov D, Andalman AS, Fee MS (2008) A specialized forebrain circuit for vocal babbling in the juvenile songbird. Science 320:630-634. CrossRef Medline

Balmer TS, Carels VM, Frisch JL, Nick TA (2009) Modulation of perineuronal nets and parvalbumin with developmental song learning. J Neurosci 29:12878-12885. CrossRef Medline

Bauer EE, Coleman MJ, Roberts TF, Roy A, Prather JF, Mooney R (2008) A synaptic basis for auditory-vocal integration in the songbird. J Neurosci 28:1509-1522. CrossRef Medline

Bottjer SW, Miesner EA, Arnold AP (1984) Forebrain lesions disrupt development but not maintenance of song in passerine birds. Science 224:901903. CrossRef Medline

Brainard MS, Doupe AJ (2000) Interruption of a basal ganglia-forebrain circuit prevents plasticity of learned vocalizations. Nature 404:762-766. CrossRef Medline

Charlesworth JD, Warren TL, Brainard MS (2012) Covert skill learning in a cortical-basal ganglia circuit. Nature 486:251-255. CrossRef Medline

Denisenko-Nehrbass NI, Jarvis E, Scharff C, Nottebohm F, Mello CV (2000) Site-specific retinoic acid production in the brain of adult songbirds. Neuron 27:359-370. CrossRef Medline

Eales LA (1985) Song learning in zebra finches: some effects of song model availability on what is learnt and when. Anim Behav 33:1293-1300. CrossRef

Guo JU, Su Y, Zhong C, Ming GL, Song H (2011a) Hydroxylation of 5-methylcytosine by TET1 promotes active DNA demethylation in the adult brain. Cell 145:423-434. CrossRef Medline

Guo JU, Ma DK, Mo H, Ball MP, Jang MH, Bonaguidi MA, Balazer JA, Eaves HL, Xie B, Ford E, Zhang K, Ming GL, Gao Y, Song H (2011b) Neuronal activity modifies the DNA methylation landscape in the adult brain. Nat Neurosci 14:1345-1351. CrossRef Medline

Hahnloser RH, Kozhevnikov AA, Fee MS (2002) An ultra-sparse code underlies the generation of neural sequences in a songbird. Nature 419:65-70. CrossRef Medline

Hensch TK (2004) Critical period regulation. Annu Rev Neurosci 27:549_ 579. CrossRef Medline

Herrmann K, Arnold AP (1991) The development of afferent projections to the robust archistriatal nucleus in male zebra finches: a quantitative electron microscopic study. J Neurosci 11:2063-2074. Medline

Hilliard AT, Miller JE, Fraley ER, Horvath S, White SA (2012) Molecular microcircuitry underlies functional specification in a basal ganglia circuit dedicated to vocal learning. Neuron 73:537-552. CrossRef Medline

Horita H, Wada K, Jarvis ED (2008) Early onset of deafening-induced song 
deterioration and differential requirements of the pallial-basal ganglia vocal pathway. Eur J Neurosci 28:2519-2532. CrossRef Medline

Horita H, Kobayashi M, Liu WC, Oka K, Jarvis ED, Wada K (2012) Specialized motor-driven dusp1 expression in the song systems of multiple lineages of vocal learning birds. PLoS One 7:e42173. CrossRef Medline

Immelmann K (1969) Song development in the zebra finch and other estrildid finches. In: Bird vocalizations (Hinde R, ed), pp 61-74. Cambridge, UK: Cambridge UP.

Jin H, Clayton DF (1997a) Synelfin regulation during the critical period for song learning in normal and isolated juvenile zebra finches. Neurobiol Learn Mem 68:271-284. CrossRef Medline

Jin H, Clayton DF (1997b) Localized changes in immediate-early gene regulation during sensory and motor learning in zebra finches. Neuron 19: 1049-1059. CrossRef Medline

Jones MW, Errington ML, French PJ, Fine A, Bliss TV, Garel S, Charnay P, Bozon B, Laroche S, Davis S (2001) A requirement for the immediate early gene Zif268 in the expression of late LTP and long-term memories. Nat Neurosci 4:289-296. CrossRef Medline

Kao MH, Doupe AJ, Brainard MS (2005) Contributions of an avian basal ganglia-forebrain circuit to real-time modulation of song. Nature 433: 638-643. CrossRef Medline

Knudsen EI (2004) Sensitive periods in the development of the brain and behavior. J Cogn Neurosci 16:1412-1425. CrossRef Medline

Kojima S, Kao MH, Doupe AJ (2013) Task-related "cortical" bursting depends critically on basal ganglia input and is linked to vocal plasticity. Proc Natl Acad Sci U S A 110:4756-4761. CrossRef Medline

Konishi M (1965) Effects of deafening on song development in American robins and black-headed grobeaks. Zeitschrift Tierpsychologie 22:584-599.

Kroodsma DE, Pickert R (1984) Sensitive phases for song learning: effects of social interaction and individual variation. Anim Behav 32:389-394. CrossRef

Kubikova L, Wada K, Jarvis ED (2010) Dopamine receptors in a songbird brain. J Comp Neurol 518:741-769. CrossRef Medline

Langfelder P, Horvath S (2008) WGCNA: an R package for weighted correlation network analysis. BMC Bioinformatics 9:559. CrossRef Medline

Leonardo A, Konishi M (1999) Decrystallization of adult birdsong by perturbation of auditory feedback. Nature 399:466-470. CrossRef Medline

Li XC, Jarvis ED, Alvarez-Borda B, Lim DA, Nottebohm F (2000) A relationship between behavior, neurotrophin expression, and new neuron survival. Proc Natl Acad Sci U S A 97:8584-8589. CrossRef Medline

Li X, Wang XJ, Tannenhauser J, Podell S, Mukherjee P, Hertel M, Biane J, Masuda S, Nottebohm F, Gaasterland T (2007) Genomic resources for songbird research and their use in characterizing gene expression during brain development. Proc Natl Acad Sci U S A 104:6834-6839. CrossRef Medline

Lombardino AJ, Nottebohm F (2000) Age at deafening affects the stability of learned song in adult male zebra finches. J Neurosci 20:5054-5064. Medline

Ma DK, Jang MH, Guo JU, Kitabatake Y, Chang ML, Pow-Anpongkul N, Flavell RA, Lu B, Ming GL, Song H (2009) Neuronal activity-induced Gadd45b promotes epigenetic DNA demethylation and adult neurogenesis. Science 323:1074-1077. CrossRef Medline

Marler P, Sherman V (1983) Song structure without auditory feedback: emendations of the auditory template hypothesis. J Neurosci 3:517-531. Medline

Matsunaga E, Suzuki K, Kato S, Kurotani T, Kobayashi K, Okanoya K (2011) Dynamic expression of cadherins regulates vocal development in a songbird. PLoS One 6:e25272. CrossRef Medline

Michod D, Bartesaghi S, Khelifi A, Bellodi C, Berliocchi L, Nicotera P, Salomoni P (2012) Calcium-dependent dephosphorylation of the histone chaperone DAXX regulates H3.3 loading and transcription upon neuronal activation. Neuron 74:122-135. CrossRef Medline

Nordeen KW, Nordeen EJ (1992) Auditory feedback is necessary for the maintenance of stereotyped song in adult zebra finches. Behav Neural Biol 57:58-66. CrossRef Medline

Nowicki S, Searcy WA, Peters S (2002) Brain development, song learning and mate choice in birds: a review and experimental test of the "nutritional stress hypothesis." J Comp Physiol A Neuroethol Sens Neural Behav Physiol 188:1003-1014. CrossRef Medline
Ölveczky BP, Andalman AS, Fee MS (2005) Vocal experimentation in the juvenile songbird requires a basal ganglia circuit. PLoS Biol 3:e153. CrossRef Medline

Poopatanapong A, Teramitsu I, Byun JS, Vician LJ, Herschman HR, White SA (2006) Singing, but not seizure, induces synaptotagmin IV in zebra finch song circuit nuclei. J Neurobiol 66:1613-1629. CrossRef Medline

Price P (1979) Developmental determinants of structure in zebra finch song. J Comp Physiol Psychol 93:260-277. CrossRef

Replogle K, Arnold AP, Ball GF, Band M, Bensch S, Brenowitz EA, Dong S, Drnevich J, Ferris M, George JM, Gong G, Hasselquist D, Hernandez AG, Kim R, Lewin HA, Liu L, Lovell PV, Mello CV, Naurin S, Rodriguez-Zas S, Thimmapuram J, Wade J, Clayton DF (2008) The Songbird Neurogenomics (SoNG) Initiative: community-based tools and strategies for study of brain gene function and evolution. BMC Genomics 9:131. CrossRef Medline

Ruben RJ (1997) A time frame of critical/sensitive periods of language development. Acta Otolaryngol 117:202-205. CrossRef Medline

Sakaguchi H (2004) Effect of social factors on the development of PKC expression in songbird brain. Neuroreport 15:2819-2823. Medline

Scharff C, Nottebohm F (1991) A comparative study of the behavioral deficits following lesions of various parts of the zebra finch song system: implications for vocal learning. J Neurosci 11:2896-2913. Medline

Soderstrom K, Tian Q (2006) Developmental pattern of CB1 cannabinoid receptor immunoreactivity in brain regions important to zebra finch (Taeniopygia guttata) song learning and control. J Comp Neurol 496: 739-758. CrossRef Medline

Stark LL, Perkel DJ (1999) Two-stage, input-specific synaptic maturation in a nucleus essential for vocal production in the zebra finch. J Neurosci 19:9107-9116. Medline

Tchernichovski O, Nottebohm F (1998) Social inhibition of song imitation among sibling male zebra finches. Proc Natl Acad Sci U S A 95:89518956. CrossRef Medline

Tchernichovski O, Nottebohm F, Ho CE, Pesaran B, Mitra PP (2000) A procedure for an automated measurement of song similarity. Anim Behav 59:1167-1176. CrossRef Medline

Teramitsu I, Poopatanapong A, Torrisi S, White SA (2010) Striatal FoxP2 is actively regulated during songbird sensorimotor learning. PLoS One 5:e8548. CrossRef Medline

Tschida KA, Mooney R (2012) Deafening drives cell-type-specific changes to dendritic spines in a sensorimotor nucleus important to learned vocalizations. Neuron 73:1028-1039. CrossRef Medline

Wada K, Sakaguchi H, Jarvis ED, Hagiwara M (2004) Differential expression of glutamate receptors in avian neural pathways for learned vocalization. J Comp Neurol 476:44-64. CrossRef Medline

Wada K, Howard JT, McConnell P, Whitney O, Lints T, Rivas MV, Horita H, Patterson MA, White SA, Scharff C, Haesler S, Zhao S, Sakaguchi H, Hagiwara M, Shiraki T, Hirozane-Kishikawa T, Skene P, Hayashizaki Y, Carninci P, Jarvis ED (2006) A molecular neuroethological approach for identifying and characterizing a cascade of behaviorally regulated genes. Proc Natl Acad Sci U S A 103:15212-15217. CrossRef Medline

Warren WC, Clayton DF, Ellegren H, Arnold AP, Hillier LW, Künstner A, Searle S, White S, Vilella AJ, Fairley S, Heger A, Kong L, Ponting CP, Jarvis ED, Mello CV, Minx P, Lovell P, Velho TA, Ferris M, Balakrishnan CN, et al. (2010) The genome of a songbird. Nature 464:757-762. CrossRef Medline

Woolley SC, Doupe AJ (2008) Social context-induced song variation affects female behavior and gene expression. PLoS Biol 6:e62. CrossRef Medline

Wu W, Thompson JA, Bertram R, Johnson F (2008) A statistical method for quantifying songbird phonology and syntax. J Neurosci Methods 174: 147-154. CrossRef Medline

Yu AC, Margoliash D (1996) Temporal hierarchical control of singing in birds. Science 273:1871-1875. CrossRef Medline

Zann RA (1996) The zebra finch: a synthesis of field and laboratory studies, pp 198-247. Oxford, UK: Oxford UP.

Zhang B, Horvath S (2005) A general framework for weighted gene coexpression network analysis. Stat Appl Genet Mol Biol 4:Article17. CrossRef Medline 